\title{
Mathematics for Maths Anxious Tertiary Students: Integrating the cognitive and affective domains using interactive multimedia
}

\author{
JANET TAYLOR and LINDA GALLIGAN
}

\begin{abstract}
Today, commencing university students come from a diversity of backgrounds and have a broad range of abilities and attitudes. It is well known that attitudes towards mathematics, especially mathematics anxiety, can affect students' performance to the extent that mathematics is often seen as a barrier to success by many. This paper reports on the design, development and evaluation of an interactive multimedia resource designed to explicitly address students' beliefs and attitudes towards mathematics by following five characters as they progress through the highs and low of studying a preparatory mathematics course. The resource was built within two theoretical frameworks, one related to effective numeracy teaching (Marr and Helme 1991) and the other related to effective educational technology development (Laurillard 2002). Further, it uses a number of multimedia alternatives (video, audio, animations, diarying, interactive examples and self assessment) to encourage students to feel part of a group, to reflect on their feelings and beliefs about mathematics, to expose students to authentic problem solving and generally build confidence through practice and self-assessment. Evaluation of the resource indicated that it encouraged students to value their own mathematical ability and helped to build confidence, while developing mathematical problem solving skills. The evaluation clearly demonstrated that it is possible to address the affective domain through multimedia initiatives and that this can complement the current focus on computer mediated communication as the primary method of addressing affective goals within the online environment.
\end{abstract}

\section{Introduction}

To be successful at university studies, students need to be academically numerate. This involves not only skills in manipulating and interpreting quantitative components of tertiary curricula, but having the confidence to engage with these components. In Australia, universities are being required to cater for a growing diversity of students who are often not prepared for the academic numeracy rigours of their discipline. Such students are often anxious about studying mathematics at any level, whether 
it is in a traditional mathematics based course (for example, engineering or science) or a non-mathematical course (for example, nursing or business). In order to assist this diverse population, universities have been searching for alternative methods to support students prior to and after entering undergraduate studies.

It is clear that in the search for alternative methods, the importance of the relationship between the affective and cognitive aspects of student learning cannot be ignored. This relationship is one of the lynchpins of constructivist learning theory, and instructional programs in mathematics, especially those designed for adult students returning to study mathematics, must develop both aspects simultaneously to be effective. In support of this, poststructuralists believe that the learning of mathematics is deeply bound in socially organised activities and systems of meaning (Agre 1997), and that students need to communicate, argue and reflect in a social environment. Bandura's (1997) social cognitive theory maintains it is students' beliefs about the value of a learning activity, their expectation of success and their enjoyment of it that will motivate them to undertake it (Pintrich and de Groot 1990). Such components of the affective domain have been discussed widely in the literature for many years (eg Tobias 1993, Higbee and Thomas 1999), especially in the adult education literature where historically, high levels of mathematics anxiety (for example) have been recorded in adult students returning to university study (Benn and Burton 1993, Benn 1997, O'Donoghue 2000, Taylor and Mohr 2001). The relationship between cognition, as measured by performance, and mathematics anxiety and other measures of the affective domain (mathematics self concept, mathematics self efficacy, and joy and beliefs about mathematics), have also been widely reported (Pajares 1996, Higbee and Thomas 1999, Hsiu-Zu, Sentark, Lam, Zimmer, Hong, Okamoto, Nakazawa and Wang 2002, Cates and Rhymer 2003, Ma and Xu 2004, Stevens, Olivarez, Lan and TallentRunnels 2004). Although these relationships have not been proven to be strong, many researchers are still concerned about the nature of the relationship. For example, Evans (1999) believes that affect has a strong influence on the ability of students to transfer mathematical skills from one context to another, and argues that this has been largely ignored in accounts of mathematical thinking. Researchers working with adult students report observing high levels of mathematics anxiety (Mackenzie 2002, Perry 2004) and express concerns that when this is associated with poor preparedness, poor mathematical proficiency can develop and be a barrier to further education experiences (Benn and Burton 1993, Benn 1997, O’Donoghue 2000). 
In the university sector, the mathematical preparedness of students has been a concern for many years, not only in mathematics based programs (Learning and Teaching Support Network 2005, Coutis, Cuthbert and MacGillvray 2002) but also in non-mathematical ones, such as nursing (Pozehl 1996). Moreover, many commencing students are also reported to have high levels of mathematics anxiety (Mackenzie 2002, Perry 2004). This research has been reinforced over the years by the authors' work in the tertiary context for bridging and undergraduate students. For example, a series of studies, involving over 600 students enrolled in a Tertiary Preparation Program, has been undertaken using both surveys and interviews to investigate the role of affective factors on success (Taylor 1995, Taylor and Mohr 2001, Carmichael and Taylor 2005, Carmichael, Dunn and Taylor 2006). Results indicate that enjoyment, confidence and self-efficacy are generally lower in adult students than those seen in recent school leavers (Taylor and Mohr 2001), and are often accompanied by poor mathematical proficiency skills (Taylor 1995, Carmichael, Dunn and Taylor 2006). Particular groups of undergraduate students can also show poor attitudes and mathematical skills. For example, some nursing students are not only anxious about mathematics, but their basic mathematics skills are often below desired entry levels (Galligan 1999, Galligan and Taylor 2005).

Marr and Helme (1991) provide curriculum solutions to this unpreparedness in their work with teachers of basic numeracy in which they present a pedagogical framework that incorporates strategies for effective face-to-face teaching to address mathematics anxiety. These solutions include:

- realisation that mathematics anxiety exists and exhibits itself in different ways with different people

- identification with others in the same situation

- demonstration that they have mathematical skills already

- $\quad$ exemplars and activities on how to solve mathematical problems

- $\quad$ strategies to solve non-routine problems using problem solving techniques

- exemplars and activities involving group discussions

- $\quad$ examples and activities involving mathematics that occurs in everyday life to help understand concepts underlying procedural knowledge students often possess

- $\quad$ examples and activities that indicate that there is more than one way to solve a problem

- $\quad$ ways in which they can assess their own progress

- $\quad$ realistic stories of success. 
In 2001, at the University of Southern Queensland, Taylor and Mohr reported on how this framework could be extended into the traditional (print based) distance education of students who exhibited anxiety and other poor attitudes to mathematics. This was later extended to video (Taylor and Galligan 2002) and online multimedia packages designed to support undergraduate students (Taylor 2002). As outlined in the following sections, as new technologies became available and accessible, an integration of these approaches using multimedia was the next step in the development of a mathematics programs for adult students, to improve their access and engagement while studying at a distance or in isolation.

Laurillard's 'Conversational Framework' (2002) for the effective use of technology was chosen to develop the program further. This framework matches well with Marr and Helme's (1991) 'effective pedagogy' in that it espouses that 'effective technology based pedagogy' must include discursive, adaptive, interactive and reflective components. That is, for each of these components, the learner must not only have access to the major conceptions being explained or advanced, but must also be able to act on these explanations, to obtain feedback on their own conceptions, and be able to adapt as a result of reflection. This process can occur in any teachinglearning situation but in the case of educational technology a dialogue between a teacher and the student is developed through a multimedia medium.

This paper reports on the design, implementation and evaluation of an interactive multimedia initiative that aimed to address explicitly the components of the affective domain in conjunction with cognitive achievement. The initiative, referred to as 'the system' below, is grounded in research on mathematics anxiety and framed within the pedagogies of Marr and Helme (1991) and Laurillard (2002).

\section{The students}

Students were located at The University of Southern Queensland (USQ), a large multi-mode regional university (26000 students in 2005; 70\% mature aged) in eastern Australia. Students targeted for this development were found in two places:

- $\quad$ in bridging programs, such as the USQ Tertiary Preparation Program (TPP), where up to 400 adult students are routinely enrolled each semester in a preparatory mathematics course offered only at a distance; and

- $\quad$ as participants in academic learning support programs, such as USQ's Learning Centre, which handles approximately 1000 mathematics inquiries per year from on-campus and distance education undergraduate students. 


\title{
Architecture of the system
}

To create a collaborative, interactive and reflective environment as envisioned by Laurillard's Conversational Framework, the system focused on the experiences and stories of five characters (Table 1) who were enrolled in an introductory mathematics course. The characters were from five different backgrounds and were based on composites of real characters the authors have met in their teaching experiences. The system developed from a traditional 20 minute video (VHS) described in Taylor and Galligan (2002), to a CD ROM with the capacity to move to online delivery.

\begin{abstract}
Mary-Anne is a single mother, aged 35 , who has secretarial training and experience. She has enrolled parttime at University to prove that she can still do it.
\end{abstract}

David is a mature-aged external student, aged 35. He is a farm mechanic by trade but now wants to be a teacher.

Lenny is an Aboriginal artist, aged 38, who has returned to study business externally.

Cindy is 25 and from Asia. She needs to study statistics in order to qualify as a psychologist.

Susan has just left school to study nursing. She is 18 and is studying full-time

\section{Table 1: Descriptions of the five characters used to direct the initiative.}

The initiative is designed to address all of the principles of teaching and strategies to overcome mathematics anxiety detailed previously. The multimedia initiative uses a story telling approach to follow the characters through the highs and lows of studying as they use their own experiences to overcome their fears of mathematics and prepare themselves for success in tertiary studies such as nursing, teaching, psychology and business. Each character is brought to life through images, text based life histories, video and audio clips of their participation in mathematics activities, and personal written reflections. Each is further identified with a particular mathematics topic. For example, Lenny is always associated with the fractions topics. In 
conjunction with the story telling approach, students using the CD-ROM will be able to:

- $\quad$ see video clips of the characters solving mathematics problems in context

- $\quad$ see video clips of the characters involved in group problem solving sessions

- $\quad$ view and hear more formal instructional sessions which include animations and voice overs

- $\quad$ participate in interactive examples

- $\quad$ test themselves using Self Test

- $\quad$ create and print a diary of personal notes and comments.

Figure 1 details the storyboard structure for the initiative. Five mathematical topics were covered including whole numbers, calculations, negative numbers, fractions, and order of calculations.

In addition to sections on mathematical examples (with interactive tools and animations) and a diary (with note taking and a reflective journal), the CD-ROM uses a number of different techniques, outlined below, to engage the students and to address the objectives of the initiative.

\section{Video story and group discussion - video and text}

The video story aims to put mathematics in a relevant context by getting the characters to discuss mathematics in a real life situation. For example, under the numbers topic, a video of two people comparing costs of bricks is used to introduce the topic of large numbers. It is presented on video and explained mathematically as screen text and symbols. The group discussion aims to represent a group problem solving session in a study group setting, either in a classroom or in a private home, and shows the characters battling with a particular problem by bouncing ideas off each other, taking risks and building on individual strengths to the benefit of the group. It also aims to show the advantages of group work and how alternative solutions are possible and correct. In the group discussion activity, actors were instructed to sometimes talk directly to the camera in an attempt to involve the viewer. Both of these components involve a short video clip, linked to a written version of the spoken script (see Table 2). Beneath each clip is a formal written explanation of the mathematics involved. 


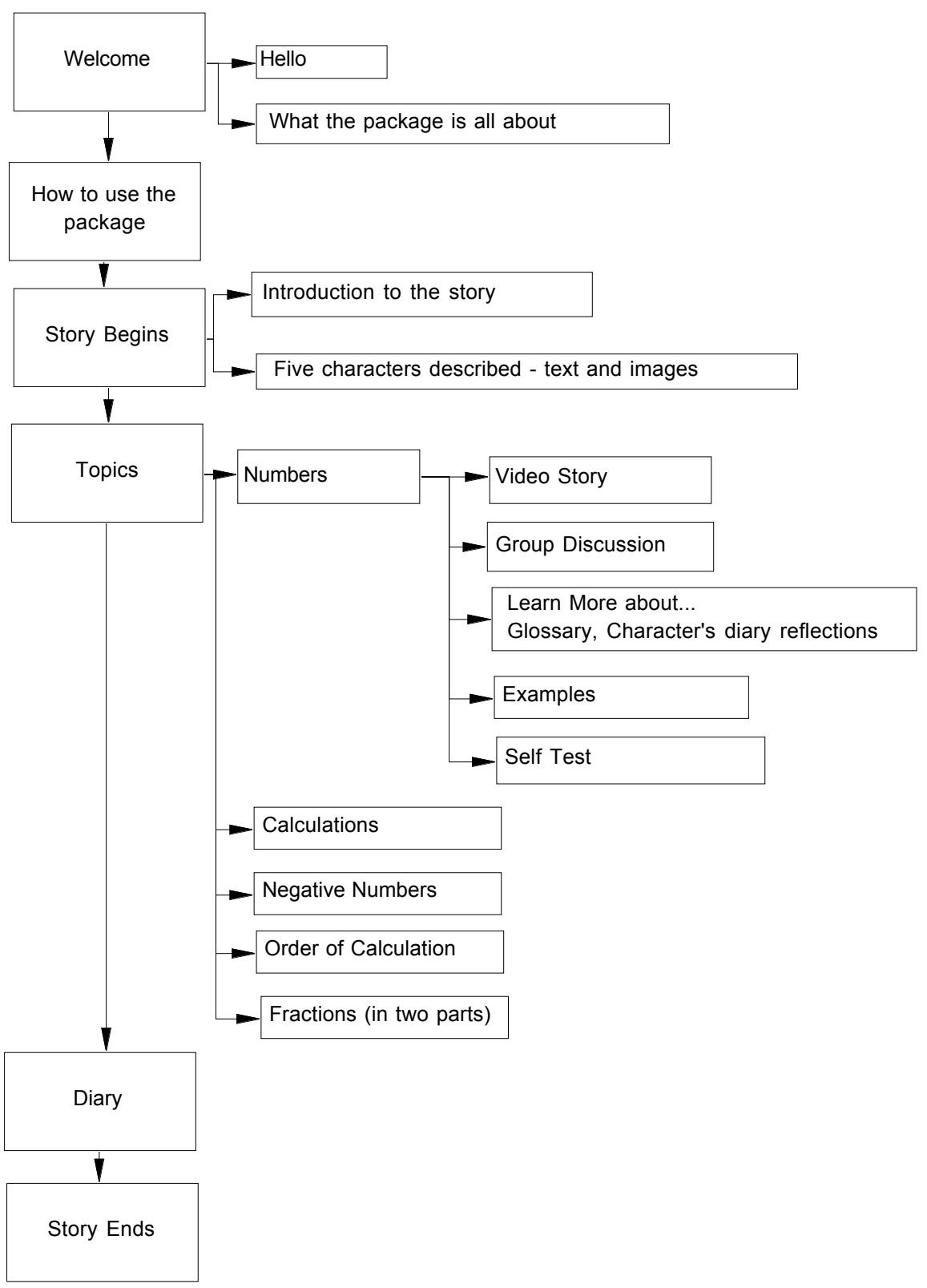

Figure 1: General story board 
Mary-Anne: (Looking at camera) Oh Hi! Good to see you. I was just saying that l've been having a look through the course outline for one of the subjects I want to do next semester. You need a degree just to read through all this and find everything. But look at this........it says there are two sections to every assignment. One part is worth 35 marks and the other is worth 15 marks.

Lenny: What, for all the assignments! Can't be many assignments then.

Mary-Anne: It says there are four, but that's too many marks don't you think? I thought it should add up to 100

David: I guess they can make it add up to how ever many marks they like....if you can do maths. What did it add up to?

Mary-Anne: I haven't really worked it out. Well ......it's four sections with 35 marks and four sections with 15 marks. Hmmm What does that make? (Susan writes in book)

Susan: I wrote it down as you were saying it. I've got four with 35 and four with 15 .

Lenny: That's easy, just write them all out and add them up. $35+35+35+35+15+15+15+15$ Let's see (using calculator) that's 200 marks.

Mary-Anne: Come on...there's got to be an easier way than that.

David: $\quad$ Let's go back to what you wrote out Susan. I'll do some maths translation here! Hey, does this mean I speak a second language? (see him writing this down on paper)

4 with 35 well that's 4 times 35 and 4 with 15 is 4 times 15

You'd have to do the multiplications and then add the answers together.

Susan: Yeah, I remember a rule like that.

Mary-Anne: Let's leave that to another time eh? All this multiplying and adding, l'm not going to worry about the marks, just think of it as four assignments, that's not many!

Lenny: $\quad$ Oh OK, but let's do some more of these distributive law things, I think l've got the hang of these...... there's five of us here let's get cracking!

(they all start to shuffle their books about)

Table 2 Extract from script from order of operations 'group discussion' 


\section{Learn more about ... - animations and audio}

This section was designed to be expository in nature and leads students through an explanation of a particular topic. It focuses primarily on spoken explanations accompanied by images and animations (Figure 2). The students, who can progress at any time using a next screen button, control the pace of instruction. At relevant points along the sequence, students are given the option to link to alternative parts of the package such as glossary, character reflections, personal diary, video stories, group discussions, examples and Self Test. 'Examples' is designed to be interactive and give students practice with completing calculations and solving more complex problems associated with each topic. Students are first encouraged to make an initial attempt, before prompts or solutions are given. Musical sounds indicate the correctness or otherwise of the attempt. Animations, text and a number of different tools are used in this component and include matching numbers, placing numbers on a scale and so on. In more complex word problems, students are given prompts to help them move through standard problem solving steps. At the end of the section students are able to link directly with Self Test if they believe they are ready.

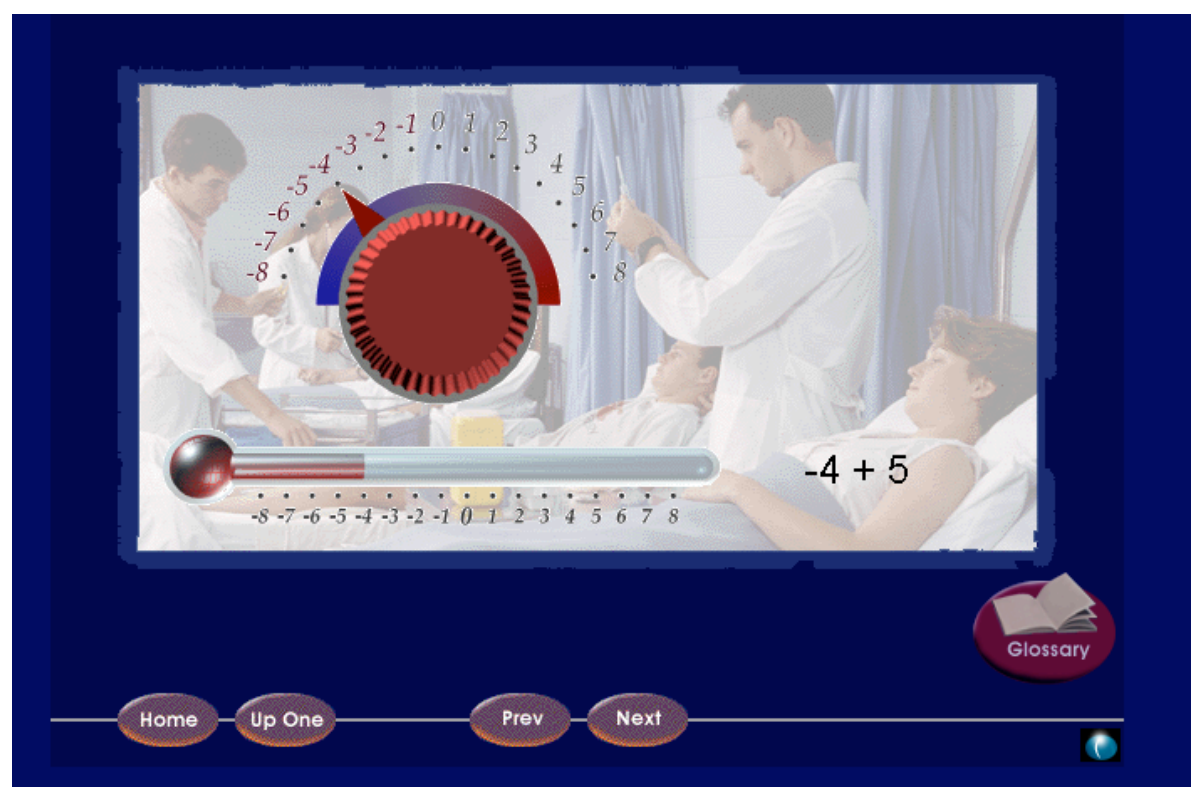

Figure 2 Screen grab of 'Learn more about' ... negative numbers 


\section{Self Test - interactive self assessment}

This section is a computer-managed test (called Self Test) that is characterised by its open structure (not based on multiple choice questions), its ability for students to submit a variety of different solutions to a mathematics question and to offer part marks for a submission. On the completion of Self Test students are provided with a plan for future study linked with learning modules, all available online within this program. Self Test is included at the end of each topic to allow students to assess their progress. On completion of Self Test students are given a list of mathematics subtopics that they have to master. The design and structure of Self Test has been described in detail elsewhere (Taylor 1998).

\section{The Diary}

The Diary is designed to encourage students to reflect on their feelings and beliefs about their mathematics achievement and to assist them to develop a set of notes associated with the course. The diary is partitioned into five mathematics topics each with a 'Notes and Reflection' section. Students can choose to make typed entries into any category or to insert links to other places within the package. The types of things that students might write in their reflections are modelled by the characters, informally, throughout the video stories and discussion groups, and formally, in 'Learn more about...' Students are also given prompts when it might be worthwhile to make such a reflection throughout the 'Learn more about...' sections. Printable copies of the diary are also possible.

\section{Evaluation}

The evaluation of the package took place in two stages. In the pilot phase, the primary aim was to determine the technical usability of the package, while in the final phase the primary aim was to determine the educational effectiveness, after technical difficulties had been overcome. The methodologies used in the evaluations were varied to suit the situation of the students involved. Fifty five different students in total, participated in both phases of the evaluation, which used one of three data collection methods:

- $\quad$ Focus group interviews of groups of students located within travelling distance of the university and following methodologies described in Lederman (1990). These interviews aimed to probe deeply into students' beliefs, feelings, thoughts and behaviour when using the software. In this research, the focus groups consisted of two groups (one of two participants and one of eleven participants) led by an experienced facilitator. Student anonymity was maintained throughout. Disccussions were taped and transcribed. Using 
grounded theory, the transcripts were analysed and key themes identified.

- A questionnaire was mailed to remote students participating in the pilot (32 students) and final evaluations (10 students). The questions aimed to gather quantitative data on the usage patterns of the participants and their general comments and beliefs about the technical and educational effectiveness of the package. The questionnaire asked students to mark on a storyboard of the program which components they had visited, and to indicate where technical difficulties had occurred. Students were then asked to comment specifically on whether the package helped with their mathematics learning and whether their feelings about mathematics had changed since using the package.

- Telephone interviews were conducted with 20 distant students after questionnaires had been received. During the interviews, after an initial discussion of their feelings and beliefs about mathematics, the students were asked specifically, about their use of the package. Then they were prompted to discuss the package by responding to the following questions:

- What parts of the package did you find useful and why?

- What parts were least useful?

- Have your feelings about mathematics changed since doing the package?

Interviews were transcribed and analysed using the same methodology as the focus group interviews.

\section{Pilot evaluation}

This stage of the evaluation used all three techniques described above. The first evaluation was conducted in a face-to-face setting, in a computer laboratory, using focus group discussion techniques, and the second, in a distance setting, was conducted through questionnaire and telephone interview. All participants were current TPP mathematics students. The face-to-face session attracted only two students while the distance evaluation involved 32 students who were sent a CD-ROM, a questionnaire, and later interviewed by telephone. As indicated above, the questionnaire asked students to mark on a storyboard of the program which components they had visited and also to indicate where technical difficulties had occurred. Students were then asked to comment specifically on whether the package helped with their mathematics learning and whether their 
feelings about mathematics had changed since using the package. In both evaluations the team found unexpected difficulties associated with the participants' lack of computer experience. The students who had technical difficulties were interviewed by phone to ascertain the nature of the difficulties, which were then logged for improvement. The majority of these difficulties were associated with unfamiliarity with program installation and browser use. Package speed also proved to be too slow during the viewing of animations and video clips. Only ten distant students were able to load the package and evaluate the learning materials. Of these ten students, seven recorded that they believed the package had assisted them with their mathematics learning, while nine believed that their feelings about mathematics had changed after using the package. Typically they made the following comments:

The video story and group discussion was interesting .. they were ordinary people using ordinary examples

The clear and easy to understand ways the story was written. The examples and the explanation of what was going wrong.

The videos and diagrams made the subject much more interestingsometimes when I am just reading (at home) it's so boring it puts me to sleep.

I am now more positive about mathematics. I think it will change anyone's idea of learning maths.

The two students who tested the package in the computer lab and were interviewed had views similar to the distance education students.

This stage of the evaluation showed that the instructional design of the package was well received and easy to follow, but that the installation process had to be further refined to account for the low level of computer expertise of many of the target group. This was accomplished over the next year.

\section{Final Evaluation}

This evaluation involved two groups of TPP students. One group of eleven students was brought together as a focus group in a university computing laboratory, in which the package had been installed on all computers. After an initial discussion of their feelings and beliefs about mathematics, the students were asked to navigate their way through the package and complete some activities lasting about one hour. The students 
were then interviewed as a group, using a series of questions as prompts. The transcript of the interview was analysed for key themes and comments.

The results of this analysis indicated that of the eleven students who participated in the study, ten declared that initially they feared, were daunted, confused or even terrified by the prospect of doing mathematics, but they were very positive about using the computer to study mathematics. All had some prior computing experience. Overall, after using the package all eleven students were very positive about the functionality and usability of the package and were keen to spend more time working through it. They found it fun to do, despite their feelings about mathematics in the beginning, and they were particularly responsive to the humour embedded within some sections. The results were as follows.

- What parts of the package did you find useful and why? Eleven responses related to the use of Examples and Self Test and the enjoyment related with the package. A typical comments was:

... you had a little hands on but you didn't feel like you were diving right in, just dipping your big toe in. And I went into the Self Test after I did that. I felt confident. So I thought that was really good, it boosts you up enough to try.

- What parts were least useful? There were two responses related to reading the instructions and use of pencil and paper to assist with Examples and Self Test. A typical comment was:

It was quite difficult doing <the examples> in my mind, when I was used to doing it on paper. And I couldn't do it on the screen, but it was good when it came up, like when I made a mistake, it came up with the working out. That was good.

- Have your feelings about mathematics changed since doing the package? Eleven responses indicated that their feelings had changed in the positive direction. A typical comments was:

It was just very relaxing, you didn't get tense or up-tight through any part of it. You felt part of what you were doing, rather than just facing a cold hard book. You were actually involved in the process.

The second group of ten students was mailed the CD-ROM together with a questionnaire and a consent form requesting them to participate in a follow-up phone interview. When interviewed, the students were encouraged to discuss technical difficulties, attitudes towards mathematics, overview of the package and its relationship to their feelings about 
mathematics, parts of the package that they felt useful and those that were not useful.

The transcripts of the interviews were analysed for key themes and comments. All students used the CD-ROM in their own home with no access to direct technical support. No technical difficulties were encountered. The analysis of the phone interviews indicated that this group of students made more specific comments relating to their fear and anxiety of mathematics than the focus group students. All ten students, although experienced computer users, declared their feelings of dread, fear or hatred of mathematics prior to commencing the course. Many also stated their concern about working alone on a mathematics course.

I am as many students scared of maths. If this $C D$ can help me in $A N Y$ way I would like to be part of the trial. I have never felt competent, but would be wonderful to feel confident.

However, after participating in the package their feelings about studying mathematics were calmer, even relaxed. Four students mentioned that they now felt that they were part of a group and one indicated that they were now encouraged to form their own study group.

The characters had the same questions as me and made me feel like being part of the group I am now encouraged to make contact with other students and form my own study group.

Doing it with the people on the $C D$ is very good for us external students $I$ think. Knowing there are people just like me is great.

Five students made comments indicating that they enjoyed the situations in which the mathematics was set, specifically signifying that they could relate to the characters and felt less isolated. Although one student indicated that he thought the acting was poor. Two students thought that the humour embedded in the storyline, especially the cartoons encouraged their enjoyment of the mathematics and was a relief from more serious book-work. Four students reported that the Video Stories exposed them to real life mathematics they had never previously contemplated and that the Group Discussion allowed them to think about new ways of solving problems.

Didn't realise how much maths in everyday life ... I am starting to see maths everywhere. 
It helped with the problem solving ... gave us different ways to do them ... I liked the way they did it ...

In relation to the mathematics presented, five students indicated that the topics of negative numbers and fractions were the most useful. Typically these are the problem areas faced by most students.

Understanding fractions was most useful, especially with the visual in the 'Learn more about'... section. Good to see how they are useful in everyday life.

In this evaluation, the diary was seen to be the least useful component. Most students viewed it and appreciated seeing the characters' diary entries, but did not want to take the time to make entries during the evaluation.

\section{Current use of the CD-ROM}

Since the evaluation of the CD-ROM, the package has been included in a number of courses as follows:

- $\quad$ it was part of the supplementary materials available in TPP mathematics in 2002 and 2003

- $\quad$ in 2004 it was incorporated into a larger course based CD-ROM and included in 330 distance education students' study package for TPP mathematics

- $\quad$ it is used within an orientation program for overseas students. Between 2002 and 2004 it was used by students who enrolled with poor numeracy skills and low levels of mathematical self concept

- $\quad$ it is used within The Learning Centre by undergraduate students whose numeracy skills are low and who lack confidence with their mathematical ability.

\section{Discussion and conclusion}

Interactive multimedia has assumed a growing place in instruction over the last decade, especially in the area of mathematics education. It has provided students with examples of mathematics in action through animations and video, control over when and what they do through interactive menus, and interactive experiences through simulations, interactive examples and self-assessment activities. However, in most of these situations students study alone, are not encouraged explicitly to value and build on their own experiences and are unaware of others in similar situations. In this educational package the underlying premise is that 
knowledge is not an entity external to the student, but is constructed within the cognitive structure of every individual. In effect, it is fundamentally personal and dependent on the experiences in prior and current learning environments and social interactions (Bostock 1998). This principle is implicit within the guidelines produced by Marr and Helme (1991) used in this development. With these in mind the course designers purposefully personalised the learning environment so that participants would feel they were a part of it rather than overlooking it. The GD-ROM presents the instruction through the eyes of students rather than an instructor. In this way we have been able to address and achieve the more subtle effects of attitudinal change through the development of characters rather than the usual development of isolated algorithms for solutions to mathematical problems.

We acknowledge limitations of the evaluative procedure. As many of our external students are geographically isolated both from our main campus and each other, it was only possible to have focus groups at the home campus. Thus, students who undertook the evaluation were self, rather than randomly, selected. However, the results do indicate that students' needs, as detailed in the introduction to this paper, were met, and after using the CD-ROM many of the aims enunciated previously were achieved. Many students' feelings of anxiety were reduced. The realization that they were not the only ones to feel this way encouraged them to feel more confident with future mathematics studies, especially when they saw that students just like them (or perhaps worse) had succeeded. The range of problem solving strategies in real world situations (Video Story) and in the Discussion Groups opened students' eyes to the wider world of mathematics that lay around them, and gave them the opportunity to reflect and then acknowledge that they had some useful mathematics skills already. The existence of the Examples and Self Test allowed the students to attempt and to prove their mastery of specific numeracy topics. Taken together, the achievement of these aims indicates that after using the CD-ROM students had increased feelings of confidence in their mathematical ability and a positive outlook towards the rest of the course. The structure of the CDROM allowed students to reflect on their own experiences and to find that they did have something to offer. They now felt more confident to take charge of their own learning. The major aims of the development were met and the development fits well within the two frameworks (Marr and Helme 1991, Laurillard 2002) put forward as goals of the design process.

In the face-to-face classroom or consultation situation, the affective needs of students are met openly through discussion and the behaviours of both the teacher and fellow students. But students study in different contexts of isolation. Some live in isolated locations, some work in different time zones and some feel isolated by their backgrounds and sentiments. More 
students than we would hope in Higher Education, view mathematics as their nemesis and have an aversion to it in all its forms. The educational design of this CD-ROM, in which attitudes and beliefs towards mathematics are explicit components, clearly helps students adjust to the study of mathematics. With the increased diversity of students entering university and the increased demand for online education, strategies need to be developed where personalised interactions can be replicated in the virtual environment. The uses of interactive multimedia of this type are many and varied for mathematics education and other education practitioners, and can complement the current focus on computer mediated communication as the primary method of addressing affective goals within the online environment.

\section{Acknowledgements}

Elizabeth Spielman, formally of Macquarie University, helped develop the original concept of this video and, with Joan Mohr, was one of the chief scriptwriters. David Ross, Joan Mohr, Iain McAlpine, Lee Sinclair, David Grant and Allan Edwards assisted with the development of the script and design. David Bull and Alison Noller assisted with the focus group interviews. The project was funded by a grant from the Committee for University Teaching and Staff Development (CUTSD) and the University of Southern Queensland.

\section{References}

Agre, P (1997) Living Math: Lave and Walkerdine on the meaning of everyday arithmetic, in Kirshner, D and Whitson, J, eds, Situated Cognition: Social, semiotic and psychological perspectives, Lawrence Earlbaum Associates, New Jersey, pp 71-82.

Bandura, A (1997) Self-Efficacy: The exercise of control, W. H. Freeman \& Co, New York.

Benn, Roseanne (1997) Adults Count Too: Mathematics for empowerment, National Institute for Adult and Community Education, Leicester, UK.

Benn, Roseanne and Burton, R (1993) Access Mathematics: A bridge over troubled waters, Fournal of Access Studies, vol 8, pp 180-190.

Benn, Roseanne and Burton, R (1994) Participation and the Mathematics Deterrent, Studies in the Education of Adults, vol 26, no 2, pp 236-249.

Bostock, S (1998) Constructivism in Mass Higher Education: A case study, British Fournal of Educational Technology, vol 29, no 3, pp 225-240. 
Carmichael, C and Taylor, J A (2005) The Analysis of Student Beliefs in a Tertiary Preparatory Mathematics Course, International Fournal of Mathematical Education in Science and Technology vol 36, no 7, pp 713-719.

Carmichael, C, Dunn, P and Taylor, J A (2006) Identifying At-Risk Students: Is it possible in a tertiary preparation course for adults?, in Grootenboer, P, Zevenbergen, R and Chinnappan, M, eds, Identities, Cultures and Learning Spaces: Proceedings of the 29th annual conference of the mathematics research group of Australasia, Mathematics Education Research Group Australasia (MERGA), Adelaide pp 107-114.

Cates, G and Rhymer, K (2003) Examining the Relationship Between Mathematics Anxiety and Mathematics Performance: An instructional hierarchy perspective, Fournal of Behavioral Education, vol 12, no 1, pp 23-35.

Coutis, P F, Cuthbert, R, and MacGillvray, H (2002) Bridging the Gap Between Assumed Knowledge and Reality: A case for supplementary learning support in tertiary Engineering Mathematics, in Turner, I and Pemberton, P, eds, Proceedings of The Fifth Biennial Engineering Mathematics and Application Conference, Institute of Engineers, Brisbane, pp 97-102.

Duffin, J and Simpson, A (2000) Understanding Their Thinking: The tension between the cognitive and the affective, in Coben, Diana, O'Donoghue, John and FitzSimons, Gail, eds Perspectives on Adults Learning Mathematics: Research and practice, Kluwer Academic Publications, Netherlands, pp 83-99.

Evans, Jeff (1999) Building Bridges: Reflections on the problem of transfer of learning in mathematics, Educational Studies in Mathematics, vol 39, pp 23-44.

Explore Math (1999-2001) Explore Learning, LLC, retrieved on 15 October 2004 from http://www.explorelearning.com/

Fogarty, Gerard J and Taylor, Janet A (1997) Learning Styles among Mature-age Students: Some comments on the approaches to studying inventory (ASI-S), Higher Education Research and Development, vol 16, no 3, pp 321-330.

Galligan, Linda (1998) Students' Confidence with their Answers to a Diagnostic Mathematics Test in Economics for External Students, in Bridging the Distance: Proceedings of the 8th Annual Conference of the Bridging Mathematics Network, Toowoomba, Queensland pp 65-70.

Galligan, Linda (2001) Analyzing Nursing Students' Drug Calculation Errors, in Bobis, Janette, Perry, Bob and Mitchelmore, Michael eds, Numeracy and Beyond, Proceedings of the 24th Annual Conference of the Mathematics Education Group of Australasia Inc. pp 241-248, Sydney, MERGA. 
Galligan, Linda and Pigozzo, Robyn (2002) Assisting Nursing Students Solve Drug Calculation Problems Using Metacognition and Error Analysis. Literacy \& Numeracy Studies, vol 12, no 1, pp 45-62.

Galligan, L and Taylor, J A (2005) Investigating Academic Numeracy in Non-mathematics Courses at University, "Bildning" and/or training: Proceedings of the 11th International Conference on Adults Learning Mathematics, held in Kungälv, Sweden, 29 June-2 July 2004, Göteborgs Universitet, Göteborg, Sweden, pp 86-95.

Higbee, J L and Thomas, P V (1999) Affective and Cognitive Factors Related to Mathematics Achievement, Fournal of Developmental Education, vol 23, no 1, pp 8-15.

Hsiu-Zu, H, Sentark, D, Lam, A, Zimmer, J, Hong, S, Okamoto, Y, Nakazawa, Y and Wang, G (2002) The Affective and Cognitive Dimensions of Maths Anxiety: A cross-national study, fournal for Research in Mathematics Education, vol 31, no 3, pp 362-379.

Laurillard, Diana (2002) Rethinking University Teaching: A conversational framework for the effective use of learning technologies, $2^{\text {nd }}$ Edition, Routledge/Falmer, London.

Lederman, L G (1990) Assessing Educational Effectiveness: The focus group interview as a technique for data collection, Communication Education, vol 38, no 2, pp 117-127.

Linda, J (2004) Math Destinations, MultiMedia Ẽ Internet@Schools, vol 11, no 1, pp 14-17.

Learning and Teaching Support Network (LTSN) (2005) Engineering Mathematics. Learning and Teaching Support Network, retrieved March 2006 at http://www.engsc.ac.uk/er/engmath/index.asp

Ma, X and Xu, J (2004) The Causal Ordering of Mathematics Anxiety and Mathematics Achievement: A longitudinal panel analysis, fournal of Adolescence, vol 27, no 2, pp 165-180.

Mackenzie, S (2002) Can We Make Maths Count in HE? Fournal of Further and Higher Education, vol 26, no 2, pp 159-171.

Marr, Beth and Helme, Sue (1991) Breaking the Maths Barrier, Language, Literacy and Asian Studies Projects (LLASP), Centre for Professional Communication, University of South Australia.

Mohr, Joan (1998) The Preliminary Phase of the Evaluation of a Bridging Mathematics Unit, in Taylor, Janet, ed, Bridging the Distance, Proceedings of the $8^{\text {th }}$ Annual Bridging Mathematics Network, Toowoomba, Australia, Bridging Mathematics Network.

National Council of Teachers of Mathematics (2002) Illuminating a new vision of school mathematics, retrieved 15 October 2004. http://illuminations.nctm.org/

O'Donoghue, John (2000) Perspectives in Teaching Adults Mathematics, in Coben, Diana, O'Donoghue, John and FitzSimons, Gail eds, 
Perspectives on Adults Learning Mathematics: Research and practice, Kluwer

Academic Publications, Netherlands, pp 229-234.

Pajares, F (1996) Self-efficacy Beliefs in Academic Settings, Review of

Educational Research, vol 66, no 4, pp 543-578.

Perry, A (2004) Decreasing Math Anxiety in College Students, College Student Journal, vol 38, no 2, pp 321-325.

Pintrich, P R and De Groot, E V (1990) Motivational and Self-Regulated Learning Components of Classroom Academic Performance. Fournal of Educational Psychology, vol 82, no 1, pp 33-40.

Pozehl, Bunny (1996) Mathematical Calculation Ability and Mathematical Anxiety of Baccalaureate Nursing Students, Fournal of Nursing Education, vol 35, no 1, pp 37-39.

Reilly, R (2004) Technology-Based Mathematics: Tools and content for teaching, assessment and accountability, MultiMedia \& Internet@Schools,vol 11,no 5,pp 30-36.

Stevens, T, Olivarez, A, Lan, W Y and Tallent-Runnels, M K (2004) Role of Mathematics Self-Efficacy and Motivation in Mathematics Performance Across Ethnicity, Fournal of Educational Research, vol 97, no 4, pp 208-221.

Taylor, Janet A (1995) Attitude to Mathematics of Adults Returning to Tertiary Study in the Distance Mode, in Hunting, R P, FitzSimons, Gail, Clarkson, Phillip, and Bishop, Alan eds, Proceedings of the International Commission on Mathematics Instruction Conference on Regional Collaboration in Mathematics Education, Melbourne, Monash University, pp 713-722.

Taylor, Janet A (1998) Self Test: A flexible self assessment package for distance and other learners, Computers and Education, vol 31, pp 319-328.

Taylor, Janet A (2002) The Evolution of Online Learning in Bridging Mathematics at a Distance: The tension between learning needs, technological innovation and access restrictions in an Australian regional university, in Statham, M ed, Crossing the Bridge, Proceedings of the 10th Australasian Bridging Mathematics Network, Auckland, July 2002, pp 67-74.

Taylor, Janet A and Galligan, Linda (2002) Overcoming Beliefs, Attitudes and Past Experiences: The use of video for adult tertiary students studying mathematics in isolation, Australian Senior Mathematics fournal, vol 16, no 1, pp 20-33.

Taylor, Janet A and Mohr, Joan (2001) Mathematics for Math Anxious Students: Development, design and evaluation of a distance education course, Fournal of Developmental Education, vol 25, no 1, pp 30-41.

Tobias, Sheila (1993) Overcoming Math Anxiety, W. W. Norton \& Company, New York. 
Zettle, R D and Houghton, L L (1998) The Relationship between Mathematics Anxiety and Social Desirability as a Function of Gender, College Student Fournal, vol 32, no 1, pp 81-87. 
